\title{
Prediksi Kehilangan Hara Pada Tanah Tererosi Menggunakan Near Infrared Reflectance Spectroscopy (NIRS)
}

\section{Predictions Of Nutrient Loss In Eroded Soil Using Near Infrared Reflectance Spectroscopy}

\author{
Muslaini Rahmi $^{1}$, Agus Arif Munawar ${ }^{1}$, Devianti ${ }^{1 *}$ \\ Program Studi Teknik Pertanian, Fakultas Pertanian, Universitas Syiah Kuala \\ *Corresponding author : devidharma28@yahoo.co.id
}

\begin{abstract}
Abstrak. Erosi merupakan suatu proses hilangnya atau terkikisnya lapisan tanah akibat adanya energi kinetik hujan yang menyebabkan terdispersinya partikel-partikel tanah. Kondisi ini menyebabkan tanah yang mengalami erosi akan menjadi miskin kandungan unsur hara dan bahan organiknya. Peristiwa ini terjadi karena unsur hara tanah banyak terdapat pada lapisan atas tanah (top soil) khususnya unsur N, P dan K sebagai penyubur tanaman. Untuk mengetahui hilangnya unsur hara akibat erosi dapat dilakukan dengan melakukan uji laboratorium pada sampel tanah yang telah tererosi, namun hal ini membutuhkan waktu yang lama, melibatkan bahan kimia lain dan merusak. Sehingga diperlukan metode baru yang dapat memprediksi kadar unsur hara tanah tererosi dengan waktu yang singkat, tanpa bahan kimia dan dapat memprediksi secara simultan. Salah satu teknologi yang dapat diterapkan untuk hal ini adalah metode Near Infrared Reflectacne Spectroscopy (NIRS). Penelitian ini bertujuan untuk memprediksi kadar unsur hara N, P dan K pada tanah tererosi dengan menggunakan teknologi NIRS dengan cepat dan akurat. Spektrum inframerah untuk sampel tanah tererosi diakuisisi menggunakan IPTEK 1516 dengan konfigurasi alur kerja (workflow) pada rentang panjang gelombang 1.000-2.500 $\mathrm{nm}$. Spektrum tersebut kemudian dikoreksi dan diperbaiki dengan metode Detrending Orde-2 (DT Orde-2) dan Multiplicative Scetter Corection (MSC) sedangkan dalam pembangunan model prediksi, metode regresi yang digunakan yaitu Partial Least Square Regression (PLS). Keakuratan model prediksi dilihat berdasarkan parameter statistika seperti korelasi (r), koefisien determinasi $\left(\mathrm{R}^{2}\right)$, Root Mean Squarred Error Calibration (RMSEC) dan Residual Predictive Deviation (RPD).
\end{abstract}

Kata Kunci : Erosi, Unsur Hara, Near Infrared Reflectance Spectroscopy

\begin{abstract}
Erosion is a process of loss or erosion of the soil layer due to the kinetic energy of rain which causes soil particles to be dispersed. This condition causes soil that is experiencing erosion to become poor in nutrients content and organic matter. This event occurs because many soil nutrients are found in the top soil, especially the elements N, P and $K$ as plant fertilizers. To determine the loss of nutrients due to erosion, laboratory tests can be carried out on eroded soil samples, but this takes a long time, involves other chemicals and it is destructive. So we need a new method that can predict the soil nutrient content eroded in a short time, without chemicals and can predict simultaneously. One technology that can be applied to this is the Near Infrared Reflectance Spectroscopy (NIRS) method. This study aims to predict the nutrient levels of N, P and $K$ in eroded soils using NIRS technology quickly and accurately. Infrared spectrum for eroded soil samples was acquired using IPTEK 1516 with a workflow configuration in the wavelength range of 1,000-2,500 $\mathrm{nm}$. The spectrum is then corrected and regenerated with the Detrending Order-2 (DT Order-2) and Multiplicative Scetter Corection (MSC) methods, while in the construction of the prediction model, the regression method used is Partial Least Square Regression (PLS). The accuracy of the prediction model is seen based on statistical parameters such as correlation (r), coefficient of determination (R2), Root Mean Squarred Error Calibration (RMSEC) and Residual Predictive Deviation (RPD).
\end{abstract}

Keywords: Erosion, Nutrients, Near Infrared Reflectance Spectroscopy

\section{PENDAHULUAN}

Erosi merupakan hilangnya tanah atau bagian-bagian tanah dari suatu tempat yang diangkut air atau angin ke tempat lain. Erosi pada dasarnya terjadi akibat interaksi kerja antara faktor-faktor iklim, vegetasi, topografi, tanah dan manusia (Arsyad, 2010). Banuwa (2013) menyatakan bahwa erosi dapat menyebabkan hilangnya lapisan atas tanah yang subur dan baik untuk pertumbuhan tanaman, serta berkurangnya kemampuan tanah untuk menyerap dan 
menahan air. Erosi yang terjadi pada suatu lahan akan mengangkut tanah dan menghasilkan sedimen. Konsentrasi unsur hara di dalam sedimen dapat mencapai 50\% lebih tinggi daripada konsentrasinya pada tanah asal (Wischmeier dan Smith, 1978 dalam Banuwa, 2013). Kehilangan hara dari permukaan tanah merupakan salah satu akibat utama dari terjadinya erosi. Sedimen hasil erosi biasanya lebih kaya unsur hara dibanding dengan tanah asalnya. Kondisi ini menyebabkan tanah yang mengalami erosi akan menjadi miskin kandungan unsur hara sehingga tanah menjadi kurang subur. Untuk mengetahui hilangnya unsur hara akibat erosi dapat dilakukan dengan melakukan uji laboratorium. Salah satu teknologi yang telah dikembangkan di era modern sekarang ini yaitu mampu memprediksi secara cepat kandungan hara pada tanah tererosi adalah teknologi Near Infrared Reflectance Spectroscopy (NIRS).

Keunggulan aplikasi NIRS adalah tidak memerlukan bahan kimia, tidak menyentuh bahan, proses deteksi cepat dan saat ini banyak diterapkan di bidang pertanian. Pengujian dengan NIRS (Near Infrared Reflectance Spectroscopy) merupakan salah satu metode nondestruktif seperti PLS (Partial Least Square Regression) yang dapat digunakan untuk menganalisis unsur hara tanah. Tujuan dari penelitian ini adalah untuk memprediksi kehilangan hara nitrogen $(\mathrm{N})$, fosfor $(\mathrm{P})$ dan kalium $(\mathrm{K})$ dalam tanah tererosi dan juga menetukan metode koreksi terbaik dan akurat.

\section{METODE PENELITIAN}

\section{Waktu dan Tempat}

Penelitian ini pada bulan September - November 2020. Pengambilan sampel tanah penelitian dilakukan di PT. Perkebunan Kurma Lembah Barbatee yang berada di Kecamatan Blang Bintang, Kabupaten Aceh Besar, Provinsi Aceh. Pengukuran erosi dilakukan di Laboratorium Fisika Tanah Program Studi Ilmu Tanah Fakultas Pertanian Universitas Syiah Kuala Banda Aceh.

\section{Alat dan Bahan}

Alat yang digunakan pada penelitian ini adalah Rainfall Simulator, instrumen Self Devoleved Fourier Transform Near Infrared Reflectance (FT-NIR), unscrambler software ${ }^{\circledR}$ $X$ version 10.5, 2 buah plot erosi, gelas ukur, kertas saring, oven, timbangan analitik, kantong plastik, alat tulis dan perlengkapan alat uji kandungan N, P dan K. Bahan yang digunakan dalam penelitian ini adalah sampel tanah di PT. Perkebunan Kurma Lembah Barbate, benih kacang tanah dan bayam.

\section{Metode Pelaksanaan}

\section{Pengambilan Sampel Tanah}

Sampel tanah yang akan digunakan dalam penelitian diambil di PT. Perkebunan Kurma Lembah Barbate. Prosedur dalam pengambilan tanahnya Siapkan cangkul beserta alat-alat pendukung lainya seperti cetok, lam dan plot erosi. Kemudian dibersihkan dan dicangkul disekitaran sampel tanah yang akan diuji sehingga membentuk petakan. Letakkan plot erosi dengan posisi tegak berdiri pada petakan tanah yang telah disiapkan. Tekan plot erosi secara perlahan-lahan sehingga semua plot erosi masuk kedalam tanah. Usahakan dalam proses pengambilan tanah tidak merusak struktur tanah aslinya atau tidak pecah pada saat pengambilan. Pengambilan bisa dibantu dengan cetok, lam agar dasar tanah tidak rusak. Angkat plot erosi beserta tanahnya , kemudian bersihkan kotoran yang menempel pada sisi plot bagian luar, ratakan permukaan tanah pada kedua ujung plot erosi. Lakukan langkahlangkah tersebut pada plot erosi berikutnya. 


\section{Pengujian Sifat Fisik Tanah}

Pengujian sifat fisik tanah meliputi: Pengukuran tekstur tanah dilakukan dengan menggunakan metode pipet. Menumbuk sampel tanah sampai halus, kemudian diayak dengan menggunakan ayakan sampai mendapatkan partikel tanah fraksi pasir, fraksi debu dan fraksi liat. Struktur tanah adalah istilah lapang yang digunakan untuk menggambarkan agrerasi tanah. Salah satu cara menetukan kemantapan agregat secara kualitatif adalah metode ayakan kering. Pengukuran porositas menggunakan metode penjenuh. Ruang pori total tanah dalam keadaan alami dinyatakan sebagai presentase volume total pori tanah yang diisi oleh udara dan air diantara partikel tanah berdasarkan nilai bobot isi dan kepadatan partikel. Pengukuran permeabilitas menggunakan metode constant head permeameter. Pada penelitian permeabilitas tanah di laboratorium dengan dasar hukum darcy dapat dilakukan dengan menggunakan alat permeabilitas. Pengukuran $\mathrm{C}$ organik menggunakan metode walkley and black.

\section{Perhitungan Dosis Pupuk}

Dosis pemberian pupuk NPK sebanyak $250 \mathrm{~kg} / \mathrm{ha}$ pada tanaman kacang tanah dan 100 $\mathrm{kg} / \mathrm{ha}$ untuk tanaman bayam, pupuk diberikan dengan cara disebar. Berikut perhitungan kebutuhan dosis pupuk dari $\mathrm{kg} / \mathrm{ha}$ dikonversikan ke jumlah gram untuk tanaman bayam dan kacang tanah dengan luas plot $0,06 \mathrm{~m}^{2}$.

$$
\text { Dosis }=\frac{\text { Luas Plot }}{10.000 \mathrm{~m}^{2}} \times \text { Kebutuhan Pupuk }
$$

\section{Perhitungan Intensitas Curah Hujan}

Intensitas curah hujan yang digunakan adalah intensitas curah hujan buatan yang dihasilkan oleh alat simulator hujan Rainfall Simulator dengan menggunakan rumus sebagai berikut :

$$
\mathrm{I}=\frac{\mathrm{V}}{\mathrm{A} \times \mathrm{t}} \times 600
$$

Keterangan :

I = Intensitas Hujan $(\mathrm{cm} / \mathrm{jam}$ atau $\mathrm{mm} / \mathrm{jam})$

$\mathrm{V} \quad=$ Volume air dalam tabung $(\mathrm{ml})$

A $\quad=$ Luas Tabung $\left(\mathrm{cm}^{2}\right)$

$\mathrm{t} \quad=$ Waktu (menit)

\section{Perhitungan Erosi}

Perhitungan jumlah tanah yang tererosi dari suatu kejadian simulasi hujan adalah sebagai berikut (Nurpilihan, dkk., 2011) :

$$
\mathrm{E}=(\mathrm{C} / \mathrm{B}) \times \mathrm{A}(\mathrm{kg} / \mathrm{plot}
$$

Keterangan :

$$
\begin{array}{ll}
\mathrm{E} & =\text { Erosi plot penelitian }(\mathrm{kg} / \mathrm{plot}) \\
\mathrm{A} & =\text { Berat tanah kering angin }(\mathrm{kg}) \\
\mathrm{B} & =\text { Sampel penegeringan oven }(\mathrm{kg}) \\
\mathrm{C} & =\text { Berat tanah kering oven }(\mathrm{kg})
\end{array}
$$




\section{Pengukuran Kadar N, P dan K Tanah di Laboratorium}

Untuk uji NPK tanah dilakukan di Laboratorium Penelitian Tanah dan Tanaman, Fakultas Pertanian Lama, Universitas Syiah Kuala Banda Aceh.

\section{Akuisisi Spektrum Infrared untuk Sampel Tanah Tererosi}

Spektrum near infrared untuk sampel tanah diakuisi dengan menggunakan instrumen infrared spectroscopy (FT-NIR) dengan konfigurasi alur kerja alat (workflow) dibangun dengan menggunakan perangkat lunak terintegrasi Thermo Operation @. Pembuatan Workflow dilakukan untuk mengatur alat agar bekerja sehingga dapat mengakuisisi spektrum diffuse reflectance sampel, lalu merata-ratakan hasilnya, dan menyimpan hasil pemindaian dalam dua bentuk file yakni *.SPA dan *.CSV.(Mouazen et al., 2010). Rentang panjang gelombang yang dipakai adalah 1000-2500 nm dengan interval sekitar $2 \mathrm{~nm}$.

\section{Metode Koreksi Spektrum Infrared}

Sebelum digunakan untuk analisa data (membangun model prediksi), spektrum NIR untuk semua sampel tanah terlebih dahulu dilakukan koreksi spektrum. Hal ini bertujuan untuk menghilangkan berbagai macam "noises" pada spektrum sampel tanah agar hasil prediksi logam berat lebih akurat (Mouazen dkk., 2010). Metode yang digunakan dalam koreksi spektrum ini adalah metode Multiplicative Scatter Correction (MSC) dan Detrending orde-2 (DT orde-2) dimana data spektrum akan diperbaiki terutama pada bagian yang banyak mengandung noise atau gangguan akibat pembauran cahaya (Munawar dkk., 2016).

\section{Model Prediksi Unsur Hara Nitrogen, Fosfor dan Kalium}

Kandungan unsur hara pada sampel tanah diprediksi berdasarkan spektrum NIR yang dihasilkan melalui proses kalibrasi model (pembangunan model). Model prediksi dibangun dengan meregresikan antara spektrum NIR (variable X) dengan kadar N, P, dan K (variabel Y) dari hasil pengukuran di laboratorium. Metode regresi yang akan digunakan adalah metode Partial Least Square (PLS).

\section{HASIL DAN PEMBAHASAN}

\section{Sifat Fisik Tanah}

Sifat fisik tanah di PT. Perkebunan Kurma Lembah Barbatee yang berada di Kecamatan Blang Bintang, Kabupaten Aceh Besar Provinsi Aceh dapat dilihat pada Tabel 1.

Tabel 1. Sifat Fisik Tanah

\begin{tabular}{ccccc}
\hline No & Hasil Analisis & Nilai & Harkat & Keterangan \\
\hline 1 & Porositas Tanah & 0,43 & - & kurang baik \\
2 & Struktur Tanah & Granular & 2 & - \\
3 & Permeabilitas Tanah & 1,84 cm/jam & 2 & lambat \\
4 & Tekstur Tanah & lempung Berpasir & - & - \\
& fraksi Pasir (sand) & $45 \%$ & - & - \\
& fraksi debu (silt) & $32 \%$ & - & - \\
& fraksi liat (clay) & $22 \%$ & - & - \\
5 & C-Organik & $1,35 \%$ & - & rendah \\
\hline
\end{tabular}

Sumber: Analisis Laboratorium (2020) 


\section{Dosis Pupuk}

Pemberian pupuk NPK 16:16:16 pada tanah dilakukan 1 minggu sebelum masa tanam. Hal ini dilakukan agar pupuk dapat tercampur dengan baik didalam tanah. Setelah itu dilakukan penanaman benih kacang tanah dan bayam. Berdasarkan (Persamaan 1) dosis pupuk untuk tanaman kacang tanah yang diberikan sebanyak $1,5 \mathrm{~g} /$ plot dan untuk dosis pupuk tanaman bayam yang diberikan sebanyak $0,6 \mathrm{~g} / \mathrm{plot}$.

\section{Pengukuran Laju Erosi}

Pengukuran erosi di laboratorium dengan meletakkan plot erosi yang berisi sampel tanah pada penyanggah dengan kemiringan $25 \%$ yang diletakan tepat dibawah Rainfall Simulator. Mengatur intensitas hujan buatan sesuai dengan yang diinginkan. Sebelum memulai percobaannya, tutup penampung limpasan dan tanah tererosi ketika alat tersebut dihidupkan. Hidupkan alat Rainfall Simulatornya dan setelah alirannya stabil sesuai dengan yang diinginkan, kemudian hidupkan stopwatch yang diatur dengan durasi selama 5 menit. Setelah 5 menit, matikan alat Rainfall Simulator tersebut, kemudian ambil penampung yang telah terisi dengan limpasan dan tanah tererosi tersebut dipindahkan ke wadah yang telah disiapkan. Saring air tampungan tersebut dengan kertas saring yang disiapkan untuk memisahkan tanah tererosi dari air limpasan tersebut. Setelah selesai disaring, kemudian ditimbang untuk mengetahui berat tanah yang tererosi tersebut.

\section{Intensitas Curah Hujan}

Berikut adalah perhitungan dari nilai intensitas hujan dengan simulasi hujan :

1. Intensitas hujan I
a. Inflow liquid $=70$
b. Tekanan $=0,3$ bar
c. Putaran nozle = I putaran $(60 \mathrm{Rev} / \mathrm{min})$
d. Sudut cakram setengah terbuka

2. Intensitas hujan II
a. Inflow liquid $=60$
b. Tekanan $=0,15$ bar
c. Putaran nozle = I putaran $(60 \mathrm{Rev} / \mathrm{min})$
d. Sudut cakram setengah terbuka

3. Intensitas hujan III
a. Inflow liquid $=50$
b. ekanan $\quad=0,1$ bar
c. Putaran nozle = I putaran $(60 \mathrm{Rev} / \mathrm{min})$
d. Sudut cakram setengah terbuka

Data percobaan intensitas hujan menggunakan rumus pada (Persamaan 2) dilihat pada Tabel 2.

Tabel 2. Percobaan Intensitas Curah Hujan

\begin{tabular}{cccc}
\hline & Luas Tampungan $\left(\mathbf{c m}^{\mathbf{2}}\right)$ & Volume Tampungan $(\mathbf{m l})$ & Intensitas Hujan $(\mathbf{m m} / \mathbf{j a m})$ \\
\hline I & 33,16625 & 37 & 133 \\
II & 33,16625 & 23 & 83 \\
III & 33,16625 & 22 & 79 \\
\hline
\end{tabular}

Sumber : Sumber : Analisis Laboratorium (2020) 


\section{Hasil Pengukuran Laju Erosi}

Plot pengukuran erosi terdiri dari 2 plot, dimana plot pengamatan pertama dengan tanaman kacang tanah dan plot pengamatan kedua dengan tanaman bayam. Pengambilan data pengukuran besarnya erosi dilakukan selama 120 menit ( $2 \mathrm{jam} / \mathrm{hari}$ ) setiap 1 minggu masa tanam, dimana pada menit 0-40 dengan intensitas hujan $133 \mathrm{~mm} / \mathrm{jam}$, pada menit 45-80 dengan intensitas hujan $83 \mathrm{~mm} / \mathrm{jam}$ dan pada menit 85-120 dengan intensitas $79 \mathrm{~mm} / \mathrm{jam}$. Hasil pengukuran aliran permukaan, erosi dan unsur hara tanah ditunjukkan pada Tabel 8 dan Tabel 9.

Tabel 8. Hasil Pengukuran Erosi dan Kehilangan Hara NPK Pada Plot Kacang Tanah

\begin{tabular}{|c|c|c|c|c|c|c|}
\hline \multirow{2}{*}{ Tanggal } & \multirow{2}{*}{$\begin{array}{c}\text { No. } \\
\text { Pengukuran }\end{array}$} & \multirow{2}{*}{$\begin{array}{c}\text { Curah } \\
\text { Hujan } \\
(\mathbf{m m})\end{array}$} & \multirow{2}{*}{$\begin{array}{l}\text { Erosi } \\
\text { Tanah } \\
\left(\mathrm{gr} / \mathrm{m}^{2}\right)\end{array}$} & \multicolumn{3}{|c|}{ Kehilangan Hara pada Tanah Tererosi } \\
\hline & & & & $\mathrm{N}$ content $(\%)$ & $\mathbf{P}(\mathbf{p p m})$ & $\mathrm{K}(\mathrm{cmol} / \mathrm{kg})$ \\
\hline \multirow[t]{3}{*}{$24 / 10 / 2020$} & $\begin{array}{l}\text { Jam 14.00- } \\
14.40 \text { WIB }\end{array}$ & 11,15 & 74,7 & 0,030 & 1,670 & 0,282 \\
\hline & $\begin{array}{l}\text { Jam 14.45- } \\
15.20 \text { WIB }\end{array}$ & 6,93 & 51,02 & 0,027 & 0,920 & 0,273 \\
\hline & $\begin{array}{l}\text { Jam 15.25- } \\
16.00 \text { WIB }\end{array}$ & 6,63 & 40,64 & 0,023 & 0,883 & 0,265 \\
\hline \multirow[t]{3}{*}{$31 / 10 / 2020$} & $\begin{array}{l}\text { Jam 14.00- } \\
14.40 \text { WIB }\end{array}$ & 11,15 & 62,75 & 0,020 & 0,842 & 0,223 \\
\hline & $\begin{array}{l}\text { Jam 14.45- } \\
15.20 \text { WIB }\end{array}$ & 6,93 & 54,71 & 0,023 & 0,733 & 0,232 \\
\hline & $\begin{array}{l}\text { Jam } 15.25- \\
16.00 \text { WIB }\end{array}$ & 6,63 & 37,27 & 0,019 & 0,850 & 0,215 \\
\hline \multirow[t]{3}{*}{$7 / 11 / 2020$} & $\begin{array}{l}\text { Jam 14.00- } \\
14.40 \text { WIB }\end{array}$ & 11,15 & 56,66 & 0,028 & 0,792 & 0,173 \\
\hline & $\begin{array}{l}\text { Jam 14.45- } \\
15.20 \text { WIB }\end{array}$ & 6,93 & 47,06 & 0,024 & 0,699 & 0,182 \\
\hline & $\begin{array}{l}\text { Jam } 15.25- \\
16.00 \text { WIB }\end{array}$ & 6,63 & 28,64 & 0,025 & 0,783 & 0,165 \\
\hline \multirow[t]{3}{*}{$14 / 11 / 2020$} & $\begin{array}{l}\text { Jam 14.00- } \\
14.40 \text { WIB }\end{array}$ & 11,15 & 46,62 & 0,017 & 0,750 & 0,132 \\
\hline & $\begin{array}{l}\text { Jam } 14.45- \\
15.20 \text { WIB }\end{array}$ & 6,93 & 34,91 & 0,013 & 0,580 & 0,115 \\
\hline & $\begin{array}{l}\text { Jam } 15.25- \\
16.00 \text { WIB }\end{array}$ & 6,63 & 28,38 & 0,010 & 0,642 & 0,123 \\
\hline
\end{tabular}

Berdasarkan hasil penelitian, diperoleh bahwa erosi pada plot pengamatan tanaman kacang tanah lebih besar dibandingkan dengan erosi yang terjadi pada plot pengamatan tanaman bayam. Hasil pengukuran pada plot kacang tanah mempunyai nilai erosi terbesar yaitu 74,7 gram $/ \mathrm{m}^{2}$ sedangkan pada plot bayam mempunyai nilai erosi terbesar yaitu 64,86 $\mathrm{gram} / \mathrm{m}^{2}$ dimana hal ini terjadi pada waktu periode hujan yang sama yaitu pada periode hujan pertama dengan tebal hujan sebesar $11,15 \mathrm{~mm}$. Hasil pengukuran NPK sampel tanah asal di labora torium dihasilkan kandungan hara nitrogen $(\mathrm{N})$ dalam tanah sebesar $0,66 \%$ yang mana nilai tersebut termasuk kriteria tinggi, fosfor $(\mathrm{P})$ sebesar 20,850 ppm termasuk kriteria sedang dan kalium (K) sebesar 7,550 cmol/kg termasuk kriteria sangat tinggi. Jumlah kehilangan hara NPK pada plot kacang tanah dan bayam dari minggu pertama sampai minggu ke-4 masingmasing $\mathrm{N}$ sebesar 0,488\%, P sebesar 17,134 ppm dan K sebesar 4,460 cmol/kg. Adapun sisa kandungan hara NPK pada tanah yaitu selisih antara nilai hara NPK pada sampel tanah asal dengan nilai hara NPK pada sampel tanah pengukuran. Untuk $\mathrm{N}$ sebesar $0,172 \%, \mathrm{P}$ sebesar 3,366 ppm dan K sebesar 3,09 cmol/kg. 
Tabel 9. Hasil Pengukuran Erosi dan Kehilangan Hara NPK Pada Plot Bayam

\begin{tabular}{|c|c|c|c|c|c|c|}
\hline \multirow{2}{*}{ Tanggal } & \multirow{2}{*}{$\begin{array}{c}\text { No. } \\
\text { Pengukuran }\end{array}$} & \multirow{2}{*}{$\begin{array}{c}\text { Curah } \\
\text { Hujan } \\
(\mathbf{m m})\end{array}$} & \multirow{2}{*}{$\begin{array}{l}\text { Erosi } \\
\text { Tanah } \\
\left(\mathrm{gr} / \mathrm{m}^{2}\right)\end{array}$} & \multicolumn{3}{|c|}{ Kehilangan Hara pada Tanah Tererosi } \\
\hline & & & & $\mathrm{N}$ content $(\%)$ & $\bar{P}(\mathbf{p p m})$ & $\mathrm{K}(\mathrm{cmol} / \mathrm{kg})$ \\
\hline \multirow[t]{3}{*}{$24 / 10 / 2020$} & $\begin{array}{l}\text { Jam 14.00- } \\
14.40 \text { WIB }\end{array}$ & 11,15 & 64,86 & 0,029 & 1,590 & 0,257 \\
\hline & $\begin{array}{l}\text { Jam } 14.45- \\
15.20 \text { WIB }\end{array}$ & 6,93 & 48,85 & 0,026 & 0,867 & 0,240 \\
\hline & $\begin{array}{l}\text { Jam 15.25- } \\
16.00 \text { WIB }\end{array}$ & 6,63 & 31,55 & 0,028 & 0,740 & 0,248 \\
\hline \multirow[t]{3}{*}{$31 / 10 / 2020$} & $\begin{array}{l}\text { Jam 14.00- } \\
14.40 \text { WIB }\end{array}$ & 11,15 & 55,18 & 0,018 & 0,685 & 0,198 \\
\hline & $\begin{array}{l}\text { Jam 14.45- } \\
15.20 \text { WIB }\end{array}$ & 6,93 & 42,75 & 0,022 & 0,725 & 0,207 \\
\hline & $\begin{array}{l}\text { Jam 15.25- } \\
16.00 \text { WIB }\end{array}$ & 6,63 & 25,61 & 0,021 & 0,508 & 0,190 \\
\hline \multirow[t]{3}{*}{$7 / 11 / 2020$} & $\begin{array}{l}\text { Jam 14.00- } \\
14.40 \text { WIB }\end{array}$ & 11,15 & 51,24 & 0,016 & 0,467 & 0,157 \\
\hline & $\begin{array}{l}\text { Jam 14.45- } \\
15.20 \text { WIB }\end{array}$ & 6,93 & 42,67 & 0,012 & 0,375 & 0,140 \\
\hline & $\begin{array}{l}\text { Jam 15.25- } \\
16.00 \text { WIB }\end{array}$ & 6,63 & 27,86 & 0,018 & 0,358 & 0,148 \\
\hline \multirow[t]{3}{*}{$14 / 11 / 2020$} & $\begin{array}{l}\text { Jam 14.00- } \\
14.40 \text { WIB }\end{array}$ & 11,15 & 45,91 & 0,013 & 0,325 & 0,107 \\
\hline & $\begin{array}{l}\text { Jam 14.45- } \\
15.20 \text { WIB }\end{array}$ & 6,93 & 33,71 & 0,015 & 0,133 & 0,098 \\
\hline & $\begin{array}{l}\text { Jam 15.25- } \\
16.00 \text { WIB }\end{array}$ & 6,63 & 21,5 & 0,011 & 0,217 & 0,090 \\
\hline
\end{tabular}

Sumber : Pengukuran Laboratorium (2020)

\section{Akuisisi Spektrum NIRS Untuk Prediksi Kadar Hara Nitrogen, Fosfor dan Kalium}

Akuisisi spektrum diambil pada saat sampel tanah dikenai radiasi Near Infrared Reflectence Spectroscopy dengan kisaran panjang gelombang 780-2500 nm akan menerima energi yang memicu terjadinya getaran dan regangan. Dari $4 \%$ energi yang dipancarkan ke bahan organik akan dipantulkan kembali ke permukaan luar (Regular reflection) dan sekitar 96\% akan masuk ke dalam bahan yang kemudian akan mengalami peyerapan, pemantulan, penyebaran dan penerusan cahaya. Saat radiasi mengenai sampel maka akan terjadi 3 fenomena yaitu diserap (absorbed), ditransmisikan (transmitted), dan dipantulkan (Reflected) (Munawar, 2008). Penelitian ini menggunakan akuisisi panjang gelombang 1000-2500 nm. Motode koreksi spektrum yang digunakan adalah metode Detrending orde-2 (DT orde-2) dan metode Multiplicative Scatter Correction (MSC) seperti terlihat pada Gambar 1 dan 2.

Digunakannya metode koreksi spektrum yaitu untuk mengurangi gangguan (noise) dalam spektrum sehingga spektrum menjadi lebih halus dan lebih rapat. Metode MSC dipilih karena metode ini mampu menghilangkan noise yang disebabkan oleh penyebaran cahaya dan juga metode MSC mampu merapatkan pita - pita spektrum awal yang renggang menjadi lebih rapat dan halus. Pada prinsipnya metode MSC mereduksi spektrum sesuai rataan penyebaran data. Metode Detrending (DT) diterapkan untuk menghilangkan trend nonlinear dalam data. Seperti pada pretreatment lainnya, hal ini dilakukan untuk mengurangi pengaruh interferensi gelombang noise, sehingga spektrum menjadi lebih halus. Hasil spektrum yang didapat setelah menggunakan metode koreksi DT dan MSC tidak terlalu berbeda, keduanya 
sama-sama mampu merapatkan pita pita spektrum yang awalnya agak renggang menjadi lebih rapat dan halus.

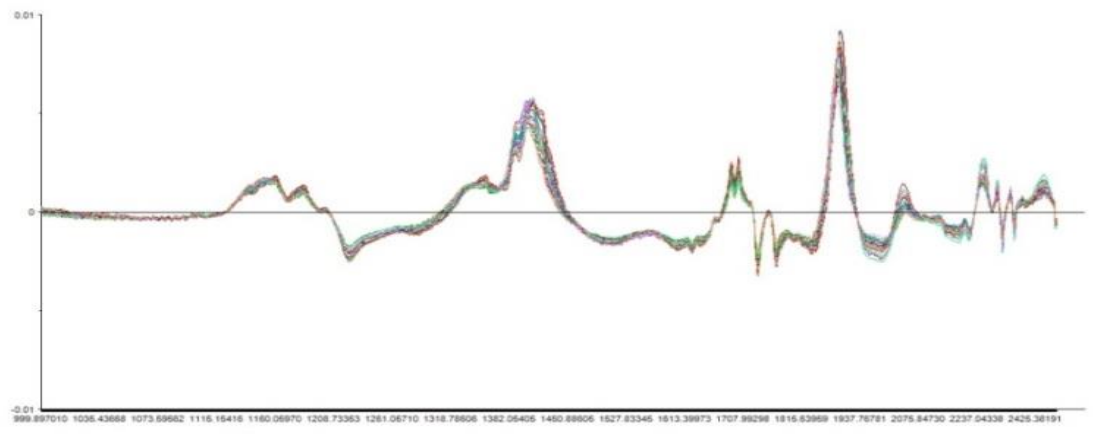

Gambar 1. Pola Spektrum Sampel Tanah Tererosi Setelah Dikoreksi Dengan Metode Detrending Orde-2 (DT orde-2)

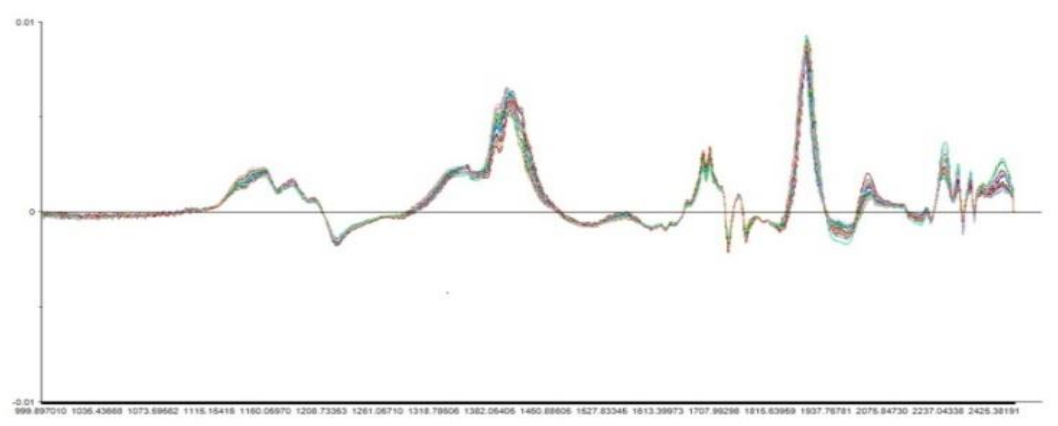

Gambar 2. Pola Spektrum Sampel Tanah Tererosi Setelah Dikoreksi Dengan Metode Multiplicative Scatter Correction (MSC)

\section{Pembangunan Model Kalibrasi}

Model kalibrasi digunakan untuk membangun model persamaan matematik yang dapat digunakan untuk memprediksi kadar hara nitrogen, fosfor dan kalium pada sampel tanah tererosi tanpa harus melakukan pengukuran langsung secara destruktif yang dapat merusak bahan. Hasil kalibrasi yang baik dapat dilihat dari nilai koefisien korelasi (r) dan koefisien determinasi $\left(\mathrm{R}^{2}\right)$ yang tinggi serta nilai standar error (RMSEC) yang rendah. Analisis dengan NIRS membutuhkan standar error yang lebih rendah dari standar deviasi (SD) data acuan. Model kalibrasi dibagun dengan meregresikan spektrum NIRS sebagai variabel X dan data aktual dari hasil uji Laboratorium digunakan sebagai variabel $\mathrm{Y}$, pembangunan model kalibrasi menggunakan metode regresi Partial Least Square (PLS). Pembangunan model kalibrasi berguna untuk mendapatkan ketelitian model informasi kadar hara nitrogen, fosfor dan kalium yang terkandung didalam sampel tanah tererosi.

\section{Hasil Kalibrasi Kadar Hara Nitrogen, Fosfor dan Kalium DT Orde-2 dan MSC}

Tingkat error dari beberapa parameter statistika data mentah yang dihasilkan dapat dilihat pada hasil kalibrasi kadar hara NPK pada tanah tererosi, kemudian hasil dari data mentah dilakukan koreksi spektrum menggunakan Detrending orde-2 dan Multiplicative Scatter Correction yang bertujuan untuk mengetahui perbedaan hasil kalibrasi antara data mentah dengan hasil kalibrasi setelah dikoreksi. Menurut (Nicolai et al., 2007; Munawar et al., 2016) model kalibrasi yang handal dan akurat adalah model dengan nilai parameter 
koefisien korelasi (r) dan RPD yang tinggi, RMSEC rendah, dan jumlah LV $<$ 9. Hasil kalibrasi metode koreksi DT Orde-2 dan MSC kadar hara nitrogen, fosfor dan kalium dapat dilihat pada Gambar 3,4,5,6,7 dan 8.

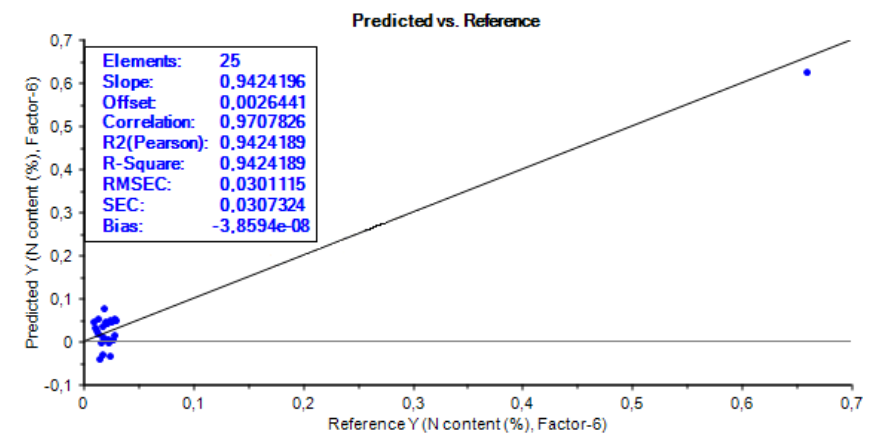

Gambar 3. Hasil Kalibrasi Kadar Hara Nitrogen dengan Metode Koreksi DT Orde-2

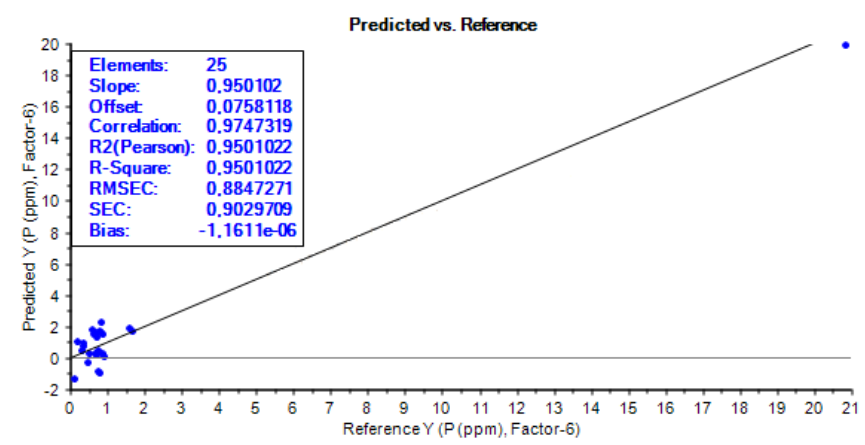

Gambar 4. Hasil Kalibrasi Kadar Hara Fosfor dengan Metode Koreksi DT Orde-2

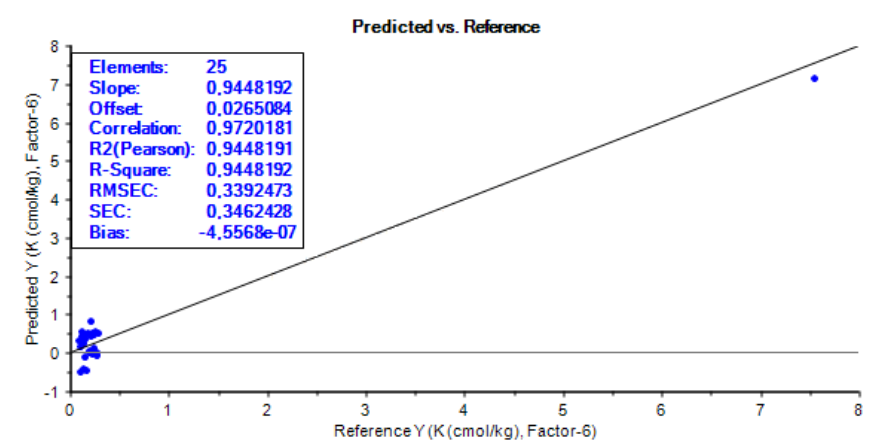

Gambar 5. Hasil Kalibrasi Kadar Hara Kalium dengan Metode Koreksi DT Orde-2

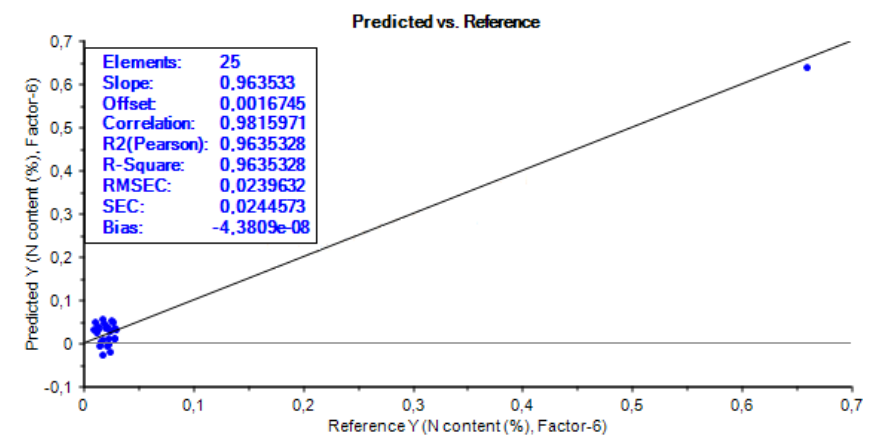

Gambar 6. Hasil Kalibrasi Kadar Hara Nitrogen dengan Metode Koreksi MSC 


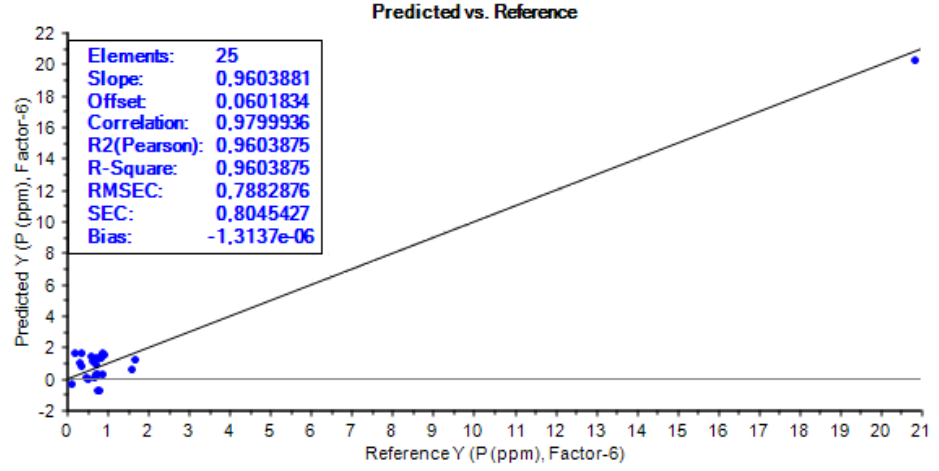

Gambar 7. Hasil Kalibrasi Kadar Hara Fosfor dengan Metode Koreksi MSC

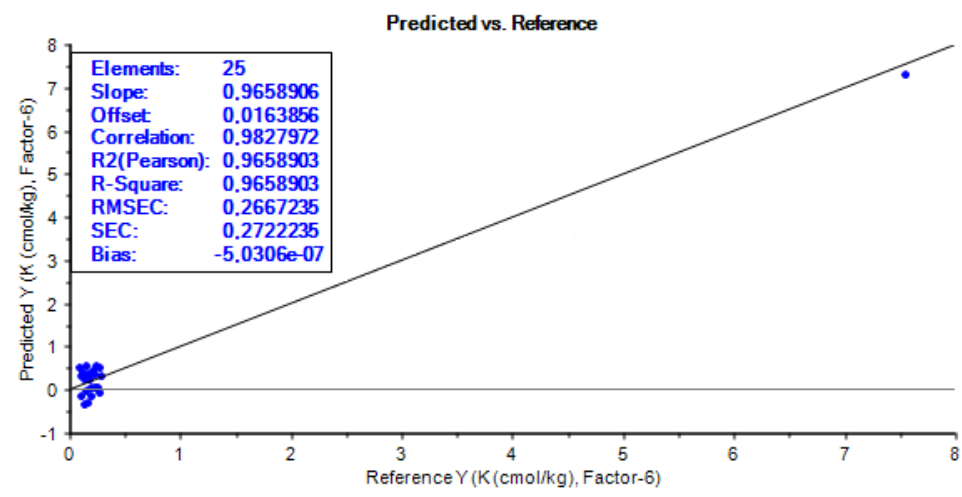

Gambar 8. Hasil Kalibrasi Kadar Hara Kalium dengan Metode Koreksi MSC

Untuk lebih jelasnya hasil parameter statistika dari masing-masing metode koreksi spektrum untuk prediksi kadar nitrogen, fosfor dan kalium dapat dilihat pada Tabel 3, 4 dan 5.

Tabel 3. Parameter Statistika Hasil Kalibrasi Kadar Hara Nitrogen

\begin{tabular}{cccccc}
\hline Metode Koreksi & $\mathbf{r}$ & $\mathbf{R}^{\mathbf{2}}$ & RMSEC & RPD & LV \\
\hline Detrending orde-2 & 0,97 & 0,94 & 0,0301 & 4,16 & 6 \\
Multiplecative Scatter Correction & 0,98 & 0,96 & 0,0239 & 5,35 & 6 \\
Interpretasi & \multicolumn{2}{c}{ Prediksi } & Yang Sangat Baik (Verygood Performance) & \\
\hline
\end{tabular}

Tabel 4. Parameter Statistika Hasil Kalibrasi Kadar Hara Fosfor

\begin{tabular}{cccccc}
\hline Metode Koreksi & r & $\mathbf{R}^{2}$ & RMSEC & RPD & LV \\
\hline Detrending orde-2 & 0,97 & 0,95 & 0,8847 & 4,56 & 6 \\
Multiplecative Scatter Correction & 0,97 & 0,96 & 0,7882 & 5,12 & 6 \\
Interpretasi & Prediksi Yang Sangat Baik (Verygood Performance) \\
\hline
\end{tabular}

Tabel 5. Parameter Statistika Hasil Kalibrasi Kadar Hara Kalium

\begin{tabular}{cccccc}
\hline Metode Koreksi & $\mathbf{r}$ & $\mathbf{R}^{2}$ & RMSEC & RPD & LV \\
\hline Detrending orde-2 & 0,97 & 0,94 & 0,3392 & 4,34 & 6 \\
Multiplecative Scatter Correction & 0,98 & 0,96 & 0,2667 & 5,52 & 6 \\
Interpretasi & Prediksi Yang Sangat Baik (Verygood Performance) \\
\hline
\end{tabular}

Hasil kalibrasi parameter statistika dari kedua metode koreksi dapat dilihat bahwa nilai kalibrasi setelah koreksi meningkat seperti pada Tabel 12. Berdasarkan dari kedua kalibrasi tersebut metode Multiplecative Scatter Correction (MSC) telah menunjukkan pediksi yang lebih baik yaitu dilihat dari nilai RPD yang paling tinggi yaitu sebesar 5,35 untuk nitrogen 5,12 untuk fosfor dan 5,52 untuk kalium. 
Tabel 6. Hasil Kalibrasi PLS Kadar Hara Nitrogen, Fosfor dan Kalium Metode Koreksi DT

\begin{tabular}{|c|c|c|c|c|c|c|c|}
\hline \multirow{3}{*}{ Spektrum } & \multirow{3}{*}{ Sampel } & \multicolumn{6}{|c|}{ Parameter } \\
\hline & & \multicolumn{2}{|c|}{ Nitrogen } & \multicolumn{2}{|c|}{ Fosfor } & \multicolumn{2}{|c|}{ Kalium } \\
\hline & & Aktual & Prediksi & Aktual & Prediksi & Aktual & Prediksi \\
\hline \multirow{25}{*}{ DT } & TA & 0,660 & 0,625 & 20,850 & 19,859 & 7,550 & 7,156 \\
\hline & EKT-1 AW & 0,030 & 0,047 & 1,670 & 1,699 & 0,282 & 0,511 \\
\hline & EKT-1 T & 0,027 & 0,002 & 0,920 & 0,096 & 0,273 & 0,003 \\
\hline & EKT-1 AK & 0,023 & $-0,004$ & 0,883 & 0,247 & 0,265 & $-0,083$ \\
\hline & EKT-2 AW & 0,020 & 0,046 & 0,842 & 1,604 & 0,223 & 0,495 \\
\hline & EKT-2 T & 0,023 & 0,004 & 0,733 & 0,190 & 0,232 & $-0,030$ \\
\hline & EKT-2 AK & 0,019 & 0,076 & 0,850 & 2,268 & 0,215 & 0,816 \\
\hline & EKT-3 AW & 0,028 & 0,048 & 0,792 & 1,707 & 0,173 & 0,471 \\
\hline & EKT-3 T & 0,024 & 0,049 & 0,699 & 1,569 & 0,182 & 0,504 \\
\hline & EKT-3 AK & 0,025 & $-0,034$ & 0,783 & $-1,002$ & 0,165 & $-0,461$ \\
\hline & EKT-4 AW & 0,017 & $-0,030$ & 0,750 & $-0,822$ & 0,132 & $-0,424$ \\
\hline & EKT-4 T & 0,013 & 0,052 & 0,580 & 1,838 & 0,115 & 0,534 \\
\hline & EKT-4 AK & 0,010 & 0,044 & 0,642 & 1,512 & 0,123 & 0,452 \\
\hline & EBY-1 AW & 0,029 & 0,052 & 1,590 & 1,935 & 0,257 & 0,535 \\
\hline & EBY-1 T & 0,026 & 0,045 & 0,867 & 1,463 & 0,240 & 0,472 \\
\hline & EBY-1 AK & 0,028 & 0,014 & 0,740 & 0,449 & 0,248 & 0,110 \\
\hline & EBY-2 AW & 0,018 & 0,010 & 0,685 & 0,236 & 0,198 & 0,055 \\
\hline & EBY-2 T & 0,022 & 0,040 & 0,725 & 1,312 & 0,207 & 0,424 \\
\hline & EBY-2 AK & 0,021 & 0,005 & 0,508 & 0,308 & 0,190 & 0,011 \\
\hline & EBY-3 AW & 0,016 & $-0,005$ & 0,467 & $-0,291$ & 0,157 & $-0,089$ \\
\hline & EBY-3 T & 0,012 & 0,023 & 0,375 & 0,724 & 0,140 & 0,222 \\
\hline & EBY-3 AK & 0,018 & 0,035 & 0,358 & 0,959 & 0,148 & 0,363 \\
\hline & EBY-4 AW & 0,013 & 0,017 & 0,325 & 0,480 & 0,107 & 0,160 \\
\hline & EBY-4 T & 0,015 & $-0,042$ & 0,133 & $-1,350$ & 0,098 & $-0,514$ \\
\hline & EBY-4 AK & 0,011 & 0,030 & 0,217 & 0,992 & 0,090 & 0,318 \\
\hline
\end{tabular}

Tabel 7. Hasil Kalibrasi PLS Kadar Hara Nitrogen, Fosfor dan Kalium Metode Koreksi MSC

\begin{tabular}{|c|c|c|c|c|c|c|c|}
\hline \multirow{3}{*}{ Spektrum } & \multirow{3}{*}{ Sampel } & \multicolumn{6}{|c|}{ Parameter } \\
\hline & & \multicolumn{2}{|c|}{ Nitrogen } & \multicolumn{2}{|c|}{ Fosfor } & \multicolumn{2}{|c|}{ Kalium } \\
\hline & & Aktual & Prediksi & Aktual & Prediksi & Aktual & Prediksi \\
\hline \multirow{20}{*}{ MSC } & TA & 0,660 & 0,639 & 20,850 & 20,195 & 7,550 & 7,317 \\
\hline & EKT-1 AW & 0,030 & 0,030 & 1,670 & 1,246 & 0,282 & 0,306 \\
\hline & EKT-1 T & 0,027 & 0,047 & 0,920 & 1,527 & 0,273 & 0,506 \\
\hline & EKT-1 AK & 0,023 & $-0,004$ & 0,883 & 0,317 & 0,265 & $-0,074$ \\
\hline & EKT-2 AW & 0,020 & 0,035 & 0,842 & 1,309 & 0,223 & 0,356 \\
\hline & EKT-2 T & 0,023 & 0,010 & 0,733 & 0,293 & 0,232 & 0,055 \\
\hline & EKT-2 AK & 0,019 & 0,044 & 0,850 & 1,375 & 0,215 & 0,443 \\
\hline & EKT-3 AW & 0,028 & 0,036 & 0,792 & 1,261 & 0,173 & 0,349 \\
\hline & EKT-3 T & 0,024 & 0,027 & 0,699 & 0,905 & 0,182 & 0,252 \\
\hline & EKT-3 AK & 0,025 & $-0,022$ & 0,783 & $-0,779$ & 0,165 & $-0,308$ \\
\hline & EKT-4 AW & 0,017 & $-0,027$ & 0,750 & $-0,803$ & 0,132 & $-0,358$ \\
\hline & EKT-4 T & 0,013 & 0,039 & 0,580 & 1,401 & 0,115 & 0,400 \\
\hline & EKT-4 AK & 0,010 & 0,030 & 0,642 & 1,071 & 0,123 & 0,306 \\
\hline & EBY-1 AW & 0,029 & 0,009 & 1,590 & 0,615 & 0,257 & 0,061 \\
\hline & EBY-1 T & 0,026 & 0,051 & 0,867 & 1,622 & 0,240 & 0,558 \\
\hline & EBY-1 AK & 0,028 & 0,009 & 0,740 & 0,230 & 0,248 & 0,063 \\
\hline & EBY-2 AW & 0,018 & 0,008 & 0,685 & 0,098 & 0,198 & 0,036 \\
\hline & EBY-2 T & 0,022 & 0,038 & 0,725 & 1,333 & 0,207 & 0,395 \\
\hline & EBY-2 AK & 0,021 & $-0,008$ & 0,508 & $-0,069$ & 0,190 & $-0,138$ \\
\hline & EBY-3 AW & 0,016 & 0,004 & 0,467 & 0,032 & 0,157 & $-0,014$ \\
\hline
\end{tabular}




\begin{tabular}{lcccccc}
\hline \hline & & & & & & \\
EBY-3 T & 0,012 & 0,025 & 0,375 & 0,832 & 0,140 & 0,231 \\
EBY-3 AK & 0,018 & 0,054 & 0,358 & 1,597 & 0,148 & 0,559 \\
EBY-4 AW & 0,013 & 0,032 & 0,325 & 1,034 & 0,107 & 0,318 \\
EBY-4 T & 0,015 & $-0,008$ & 0,133 & $-0,328$ & 0,098 & $-0,134$ \\
EBY-4 AK & 0,011 & 0,049 & 0,217 & 1,668 & 0,090 & 0,526 \\
\hline
\end{tabular}

\section{Loading Plot Kadar Hara Nitrogen, Fosfor dan Kalium}

Berdasarkan hasil model kalibrasi spektrum absorban dan reflektan NIRS pada tanah tererosi menunjukkan bahwa panjang gelombang 1000-2500 nm dapat memprediksi kadar hara nitrogen, fosfor dan kalium pada tanah tererosi. Loading plot yang didapatkan dapat menentukan panjang gelombang relavan yang dapat memprediksi kadar nitrogen, fosfor dan kalium di dalam tanah tererosi. Blanco dan Villarroya (2002) mengatakan bahwa adanya puncak dan lembah spektra NIR disebabkan karena adanya pengaruh dari kandungan kimia di dalam suatu bahan. Loading plot kadar nitrogen fosfor dan kalium dapat dilihat pada Gambar 9, 10 dan 11.

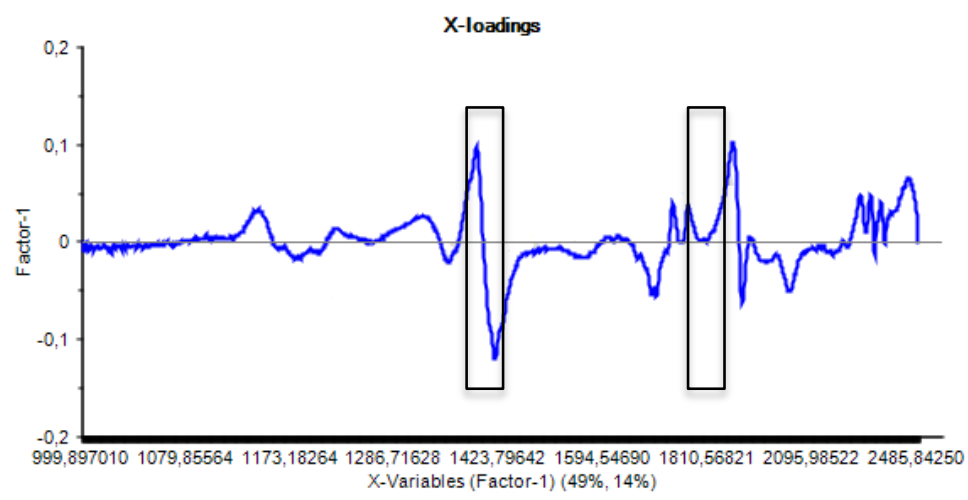

Gambar 9. Loading plot untuk Kadar Hara Nitrogen

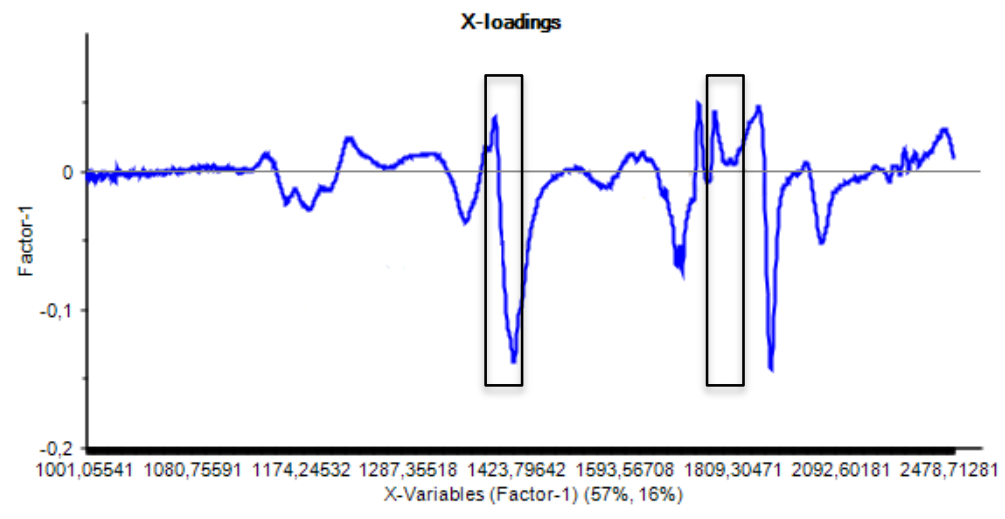

Gambar 10. Loading plot untuk Kadar Hara Fosfor 


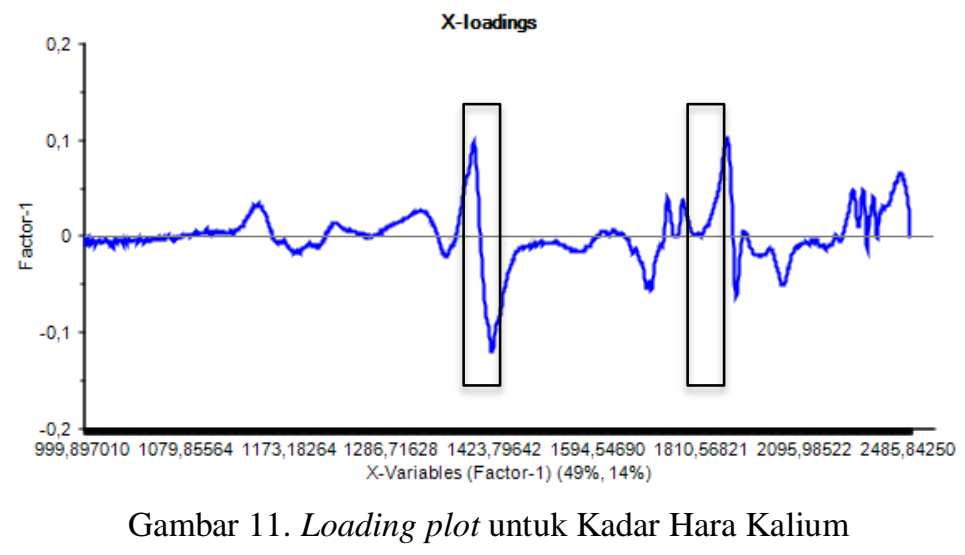

Berdasarkan Gambar 9, 10 dan 11 terlihat puncak dan lembah spektrum NIRS berada pada kisaran panjang gelombang 1393-1419 nm dan 1867-1898 nm untuk nitrogen, pada kisaran panjang gelombang 1396-1420 nm dan 1876-1900 nm untuk fosfor dan pada kisaran panjang gelombang 1392-1418 $\mathrm{nm}$ dan 1866-1895 $\mathrm{nm}$.

\section{KESIMPULAN DAN SARAN}

\subsection{Kesimpulan}

1. NIRS dengan metode Partial Least Square (PLS) ini mampu memprediksi kadar hara nitrogen, fosfor dan kalium pada tanah tererosi dengan cepat dan akurat.

2. Metode koreksi yang paling baik adalah menggunakan metode koreksi Multiplicative Scatter Correction (MSC) dengan nilai $\mathrm{r}=0,98$ dan nilai $\mathrm{R}^{2}=0,96$ serta nilai $\mathrm{RPD}=5,35$ untuk nitrogen $(\mathrm{N})$. Nilai $\mathrm{r}=0,97$ dan nilai $\mathrm{R}^{2}=0,96$ serta nilai $\mathrm{RPD}=5,12$ untuk fosfor (P). Adapun nilai $r=0,98$ dan nilai $\mathrm{R}^{2} 0,96$ serta nilai $\mathrm{RPD}=5,52$ untuk kalium $(\mathrm{K})$. Nilai parameter statistik tersebut lebih tinggi dibandingkan dengan nilai RPD pada metode koreksi Detrending orde-2 (DT orde-2).

3. Panjang gelombang yang relavan untuk memprediksi kadar hara nitrogen pada tanah tererosi yaitu pada panjang gelombang 1393-1419 nm dan 1867-1898 nm, untuk fosfor panjang gelombang 1396-1420 nm dan 1876-1900 nm dan untuk kalium pada panjang gelombang 1392-1418 $\mathrm{nm}$ dan 1866-1895 $\mathrm{nm}$.

\subsection{Saran}

Saran pada penelitian ini adalah untuk prediksi kehilangan hara pada tanah tererosi menggunakan Near Infrared Reflectance Spectroscopy (NIRS) sebaiknya dilakukan penelitian lanjutan mengenai pengukuran erosi secara langsung skala lapangan dengan kemiringan yang berbeda dan intensitas yang berbeda. 


\section{DAFTAR PUSTAKA}

Arsyad, S. 2010. Konservasi Tanah Dan Air. Edisi Kedua. IPB Press. Bogor.

Banuwa, I. S. 2013. Erosi. Kencana Prenadamedia Group. Jakarta.

Devianti, D., Sufardi, Zulfahrizal Dan A. A. Munawar. 2019. Near Infrared Reflectance Spectroscopy: Prediksi Cepat Dan Simultan Kadar Unsur Hara Makro Pada Tanah Pertanian. Laporan Penelitian. Universitas Syiah Kuala, Banda Aceh. Agritech 39 (1) : 12-19.

Mouazen A. M., W. Saeys, J. Xing, J.D. Baerdemaeker And H. Ramon. 2010. Near Infrared Spectroscopy For Agricultural Materials An Instrument Comparison. J Near Infraredspectrosc. Vol.13. 87-97.

Munawar, A. A., D. V. Hörsten, D. Mörlein, E. Pawelzik, Dan J. K. Wegener. 2013. Rapid And Non-Destructive Prediction Of Mango Sweetness And Acidity Using Near Infrared Spectroscopy. In Lecture Notes In Informatics (Lni), Proceedings Series Of The Gesellschaft Fur Informatik (Gi) (Vol. P-211).

Munawar, A. A., D. V. Hörsten, J. K. Wegener,E. Pawelzik dan D. Mörlein. 2016. Rapid And Non-Destructive Prediction Of Mango Quality Attributes Using Fourier Transform Near Infrared Spectroscopy and Chemometrics. Engineering in Agriculture, Environment and Food, 9(3), 208-215.

Nicolai, B. M., Beullens, K., Bobelyn, E., Peirs, A., Saeys, W., Theron, K. I., \& Lamertyn, J. 2007. Nondestructive Measurement Of Fruit And Vegetable Quality By Means Of Nir Spectroscopy: A Review. Postharvest Biology And Technology.46 : 99-118.

Nurpilihan, Amaru, Kharistya, Suryadi, dan Edy, 2011. Perhitungan Run off pada Lahan Curam yang Ditanami Jagung Hibrida DR Unpad, Laporan Penelitian UNPAD, Bandung. 